\title{
DESAFIOS E INOVAÇÕES NA GESTÃO DE PESSOAS DE UMA HOLDING BRASILEIRA DE ENSINO SUPERIOR
}

\author{
CHALLENGES AND INNOVATION ON PEOPLE MANAGEMENT WITHIN A BRAZILIAN \\ HIGHER EDUCATION HOLDING COMPANY
}

\section{Henrique da Silveira Zanin}

henriquezanin@usp.br

Faculdade de Direito/Universidade de São Paulo - São Paulo/SP, Brasil

http://orcid.org/0000-0002-1991-4270

\section{Leandro dos Santos Ferreira}

leandro.sferreira@una.br

Programa de Mestrado Profissional em Administração/Una - Belo Horizonte/MG, Brasil

http://orcid.org/0000-0003-1812-2340

Iris Barbosa Goulart

iris.goulart@una.br

Programa de Mestrado Profissional em Administração/Una - Belo Horizonte/MG, Brasil

http://orcid.org/0000-0003-1088-3268

\author{
Fernanda Carla Wasner Vasconcelos \\ fernanda.wasner@una.br \\ Programa de Mestrado Profissional em Administração/Una - Belo Horizonte/MG, Brasil \\ http://orcid.org/0000-0002-4102-8486
}

\section{Resumo}

Este artigo tem como objetivo identificar os desafios da gestão de pessoas de uma holding educacional e analisar as inovações no referido setor para enfrentá-los. Foi realizada uma pesquisa qualitativa, descritiva e a coleta de dados foi feita mediante entrevistas individuais e coletivas com empregados que atuam na gestão de pessoas e no jurídico da organização. Os dados foram submetidos à análise de conteúdo e confrontados com estudos teóricos. Resultados apontaram que o setor de gestão de pessoas é levado a resolver problemas que envolvem conhecimento mais amplo de gestão administrativa, marketing, jurídico, adotando inovações para solucioná-los.

Palavras-chave: Gestão de pessoas. Administração de recursos humanos. Inovação. Gestão organizacional. Gestão de departamento jurídico.

\begin{abstract}
This article aims to identify the challenges faced by the people management of a holding company of higher education and to analyze the innovation strategies adopted to tackle them. A qualitative, descriptive study was carried out, data was collected through individual and collective interviews with people who work in the people management and legal department of the organization. The data were submitted to content analysis and compared with theoretical studies. Results showed that the people management department is led to solve problems that involve other areas of knowledge, such as administrative management, marketing, legal, adopting innovative actions to solve them.
\end{abstract}

Keywords: People management. Human resources management. Innovation. Organizational management. Legal department management. 


\section{Introdução}

Até a década de 1980, o ensino universitário no Brasil constituía uma tentativa de reproduzir o modelo das instituições europeias e não apresentava um vínculo forte com o sistema produtivo. $\mathrm{O}$ acesso a este nível de ensino era reservado a jovens que vinham de classes sociais economicamente mais favorecidas e que podiam frequentar escolas que lhes garantissem sucesso nos processos seletivos adotados pelas universidades (vestibulares) ou por exíguas instituições de ensino superior da rede privada, cujos cursos tinham um alto custo.

Durante a segunda metade da década de 1990, as transformações no ambiente político, econômico e social do país passaram a exigir a qualificação dos jovens para a entrada num mercado de trabalho mais competitivo. Diante disso, o Governo Brasileiro passou a adotar medidas que definiram um novo rumo para o ensino superior no Brasil (Morrow \& Torres, 2004). Nas universidades públicas, foram implementados programas destinados a oportunizar o acesso de camadas da população antes não atendidas e na rede privada, as instituições de ensino superior tiveram maior facilidade para implementar novos cursos e para se organizarem em grandes grupos educacionais, que passaram, então, a criar novas faculdades, centros universitários ou universidades. Além disso, programas de financiamento da educação ampliaram o número de alunos na rede privada, obrigando-a a adotar novos modelos de gestão, que permitissem coordenar o trabalho de várias unidades de ensino, muitas vezes situadas em diferentes estados da federação.

A partir das novas medidas, a gestão dos grandes grupos educacionais teve de enfrentar a competitividade, procurando, assim, abordagens inovadoras. As ações de marketing precisavam garantir a atratividade de cada uma das instituições de ensino superior (IES); a gestão de pessoas passara a cobrir atividades não englobadas até então, e as instituições de ensino que compunham o grupo tiveram de se adequar ao modelo adotado pelas mantenedoras, ou holding educacional. Para garantir a qualidade do ensino, o Ministério da Educação adotou programas de avaliação dos cursos oferecidos e a gestão de pessoas teve de selecionar e manter profissionais mais qualificados capazes de lidar com tais processos de acreditação e avaliação, além dos processos corriqueiros atribuídos à área como núcleo das atividades.

Diante deste panorama histórico, analisa-se os desafios aos quais gestores educacionais estão sujeitos na implementação de medidas que viabilizam a expansão do ensino superior na rede privada. O primeiro desafio enfrentado pelos novos grupos educacionais foi adotar modelos inovadores de gestão, marcados por fusões, aquisições e abertura de capital. $\mathrm{O}$ segundo desafio consistiu em enfrentar a competitividade com outras instituições de ensino superior, atraindo e retendo alunos, mediante apresentação de diferenciais elaborados por meio de novos currículos, metodologias e marketing institucional. Para isso, surgiu outro desafio, que consistiu em redefinir o quadro de pessoal, estabelecendo parâmetros para contratação, manutenção e demissão de pessoal docente e administrativo, de forma que se mantivesse a qualidade do ensino com um grupo enxuto de empregados.

Diante do cenário do século XXI, aos gestores de pessoas apresentou-se a necessidade de adotarem procedimentos que tornassem a instituição capaz de proceder à escolha desses profissionais, enquanto, ainda, se solucionavam os processos, inclusive judiciais, advindos das demissões ocorridas. Equilibrar o atendimento a este duplo objetivo selecionar e manter os indispensáveis e dispensar os demais - é o desafio a ser analisado neste trabalho, ouvindose o setor de Gestão de Pessoas de uma holding, ou grupo, educacional de instituições de ensino superior.

Tradicionalmente, a área de Gestão de Pessoas cobre ações de captação e seleção de pessoas, contratação para os diferentes postos de trabalho, qualificação de empregados mediante ações de treinamento e desenvolvimento de pessoas e de equipes, avaliação de desempenho, bem como questões relacionadas ao afastamento de pessoal por demissão, dispensa, aposentadoria, dentre outros, sem que ocorra qualquer descontinuidade das atividades da instituição. Entretanto, para se manterem competitivas no mercado, as grandes organizações educacionais têm de enfrentar outros desafios, e, para isso, precisam adotar medidas inovadoras que as capacitem a resolver os problemas emergentes.

A crise econômica que aconteceu no país na segunda década dos anos 2000 levou à suspensão de financiamento de alguns dos programas, o que resultou na debandada de um número vultoso de alunos das instituições privadas. 
Alguns desafios se apresentaram a partir deste momento, exigindo a tomada de decisões inovadoras, capazes de garantir a sobrevivência de cada instituição.

Neste trabalho, são analisadas as dificuldades advindas deste processo de mudanças contemporâneas e as medidas tomadas pelo setor de Gestão de Pessoas de um grupos de instituições de ensino superior de grande porte para atender aos desafios apresentados desde a segunda década dos anos 2000.

Portanto, o objetivo geral consiste em identificar os principais desafios enfrentados pelo setor de Gestão de Pessoas desta holding e analisar as inovações adotadas pelo referido setor como um todo.

\section{Fundamentação teórica}

O trabalho teve significativo desenvolvimento no final do século XIX e nas duas primeiras décadas do XX. A Constituição mexicana de 1917, seguida da Constituição de Weimar, em 1919, são os primeiros registros de alçada dos direitos laborais ao patamar constitucional e da desmercantilização do trabalho, sendo a "proteção ao trabalho [...] essencialmente anticapitalista" (Comparato, 2019, p. 189).

A iminente globalização, entendida como a intensificação das relações transnacionais e a menor capacidade e soberania dos Estados de se autorregularem politicamente, o que causaria, em última análise, diminuição das condições mínimas de sobrevivência (Bauman, 1999; Santos, 2005), ocorreu ao mesmo passo do desenvolvimento tecnológico nos países ocidentais, exigindo a adoção de critérios mais adequados ao acompanhamento das atividades dos trabalhadores, visto que entendido o trabalho como categoria fundamental para a constituição do ser social (Tassigny, 2004). Nesse mesmo sentido, afirmaria Freitas Júnior (2006) que o trabalho é forma de realização do ser humano enquanto pessoa em todas as suas esferas da sociedade. Dworkin (2012), por sua vez, lembraria que deve-se buscar no trabalho e na sociedade a igualdade de oportunidades, bem-estar e êxito.

Até a década de 1920, contudo, a gestão de pessoas nas empresas se restringia à prática burocrática da contratação, que ficava a cargo do "Departamento de Pessoal", órgão da empresa que selecionava, contratava, controlava o desempenho do trabalhador, mas não desenvolvia um programa de desenvolvimento e avaliação do trabalho, o que somente se constituiria como prática décadas seguintes.

A partir da visão mais crítica introduzida pelas teorias de Administração, porém, e graças ao desenvolvimento dos estudos e pesquisas relacionados à motivação, às relações humanas, ao desenvolvimento de grupos, à liderança, atitude e comunicação, aspectos que passaram a ser consideradas na análise da produtividade, a Administração de Recursos Humanos ganhou destaque enquanto vertente única e necessária ao ambiente organizacional em atuação múltipla (Tonelli, Lacombe, \& Caldas, 2002).

A necessidade de tornar as pessoas produtivas, oferecendo o melhor de si para o rendimento do trabalho, levou as organizações a investirem numa área técnico-científica denominada Administração de Recursos Humanos (ARH). À medida que este setor das empresas recebeu a influência da gradual valorização do capital humano, a denominação Gestão de Pessoas passou a ser usada, tendo como objetivo gerenciar os comportamentos internos e potencializar o capital humano, no intuito de inserir ou manter uma mão de obra qualificada no mercado (Goulart, 2010).

Fischer (2001, p. 19) assim definiu a Gestão de pessoas:

O modelo de gestão de pessoas deve ser compreendido como o conjunto de políticas, práticas, padrões atitudinais, ações e instrumentos empregados por uma empresa para interferir no comportamento humano e direcioná-lo no ambiente de trabalho. Do ponto de vista empresarial, tais iniciativas são provenientes de diferentes instâncias organizacionais e mesclam-se com as estratégias e práticas dos próprios empregados. 
Ribeiro (2005), em mesmo sentido, observa que após o desenvolvimento de pesquisas sobre esses temas, o que era controlado, conservado e restrito passou a ser proposto, garantido e dignificado, definindo uma nova linha de pensamento.

Husek, Stefano e Grzeszczeszyn (2008, p. 2), em contribuição às atividades que seriam, segundo os autores, as que constituiriam um núcleo da Gestão de Pessoas, citariam

\footnotetext{
[a]judar a organização a alcançar seus objetivos e realizar sua missão; Proporcionar a competitividade à organização; Proporcionar à organização pessoas bem treinadas e bem motivadas; Aumentar a auto[r] realização e a satisfação das pessoas no trabalho; Desenvolver e manter a qualidade de vida no trabalho; Administrar e impulsionar mudanças; e, manter políticas éticas e comportamento socialmente responsável.
}

A Gestão de pessoas constitui, pois, um modelo de gerenciamento que visa a garantir a produtividade e o lucro mediante integração do trabalhador no contexto da organização e para isso se vale de conhecimentos derivados da pesquisa produzida em várias ciências sociais e humanas - Psicologia, Sociologia, Antropologia.

A partir do final da década de 1990, a Era do Conhecimento e o destaque dado ao elemento humano no discurso empresarial determinaram mudanças relevantes nas relações entre capital e trabalho. Este fenômeno, acrescido dos avanços tecnológicos e de mudanças rápidas na sociedade, tornou a Gestão das Pessoas indispensável na busca de talentos para as organizações (Miranda \& Miranda, 2009), de forma, ainda, que se deveria conciliar o trabalho e a liberdade para se desfrutar de bem-estar social e econômico, aquele proposto por Marx e Engels (2000), de acordo com as novas demandas dos profissionais que ingressavam naquele mercado de trabalho.

Para sobreviver, uma organização tende a espelhar o tempo e o lugar no qual está instalada e isto acontece de maneira natural, nem sempre consciente. Desse modo, os objetivos, as políticas, as estruturas organizacionais, os métodos de operar estão se alterando constantemente para acompanhar o processo de mudança sócio-políticoeconômica (Goulart, 2010).

Acompanhando as mudanças ocorridas no mundo em função do desenvolvimento econômico, político e social, verifica-se que a Gestão de Pessoas não pode se ater apenas aos aspectos relacionados à empresa e às pessoas, mas cabe a ela, na contemporaneidade, proceder à leitura e interpretação da realidade exterior à organização e refletir, nas suas ações, esta realidade.

Segundo Dias e Araújo (2008), essa área vem passando por um amplo processo de transformação, já que as empresas precisam adotar posturas estratégicas claras, amparadas por uma gestão com amplo desenvolvimento e participação. Torna-se necessário um compromisso com a força de trabalho, baseado em um ambiente que viabilize comunicação aberta e respeito mútuo buscando o envolvimento dos clientes internos e externos. Esta perspectiva estratégica não é recente, já tendo sido anunciada desde a década de 1980 por autores como Albuquerque (1987) Anthony, Perrewé e Kacmar (1996) e Ulrich (1998).

Albuquerque $(1987,1992)$ apresenta visão sistêmica do alinhamento da estratégia de Gestão de Pessoas aos objetivos organizacionais, propondo uma gestão no nível estratégico que vise a obtenção de melhores resultados para as organizações, através daqueles que a constituem.

Dias e Araújo (2008) corroboram esta visão, observando que num mundo em que a competitividade e a eficiência cada dia marcam mais fortemente os negócios, gerir pessoas estrategicamente implica compreender que as personalidades são complexas e dinâmicas e que cada pessoa é um conjunto de valores crenças e informações que interagem em todas as decisões da empresa, por isso é necessário saber interligar estes aspectos para atingir produtividade e gerar produtividade.

Freitas Filho (2013) e Freitas Filho, Campos e Sousa (2015) consideram que a inovação constitui uma alternativa de tema estratégico para as organizações, estando diretamente ligada à competitividade e à busca pela liderança no segmento de mercado onde cada organização atua, sendo cada vez mais utilizada como meio para a Gestão de Pessoas se adequar ao contexto atual. 
Para Gülsoy (2013), a inovação organizacional está intimamente ligada às políticas e práticas de recursos humanos e menciona práticas como a atração de talentos, os planos de carreira, as equipes multifuncionais, o reconhecimento e a recompensa.

Essa menciona inovação é ainda percebida na prática pelos novos laços organizacionais que têm sido criados pela Gestão de Pessoas com outras áreas departamentais, como, por exemplo, com departamentos jurídicos, para elaboração de políticas e ações de prevenção de litígios, especialmente após a Reforma Trabalhista e a diminuição da atuação dos sindicatos de trabalhadores, o que vai em sentido oposto ao afirmado por Galdino (2005), que entende ser dever do Estado moderno prover pelos direitos sociais, com prestações positivas, nas quais dever-seia incluir a proteção estatal no trabalho, por vezes diminuída.

Barros (2009) define alguns tópicos nos quais jurídico e Gestão de Pessoas podem, então, colaborar, de forma a evitar posteriores passivos trabalhistas, como discriminação e assédio no ambiente de trabalho, investigações indevidas por superiores do empregado sobre a vida privada do último. Gomes (2008), em complemente, afirma que essas violações aos direitos dos empregados podem se dar durante o contrato de trabalho, mas, também, antes do início e no momento de rescisão do vínculo de trabalho. Boucinhas Filho (2008, p. 196), por fim, afirmaria inclusive haver a discriminação por sobrequalificação, que seria o "o ato de excluir previamente algum candidato para obtenção de emprego [...] em razão dele apresentar formação superior à exigida pela complexidade das tarefas que realiza", tão presente numa sociedade capitalista com esfacelamento de direitos sociais e oportunidades de trabalho para tantos.

O grande desafio que atualmente se apresenta para organizações de grande porte da área de educação consiste em adequar o seu modelo de Gestão de Pessoas às exigências de um mercado altamente competitivo, que tem características bem diversas daquelas que marcaram a história das instituições educacionais e do mercado de trabalho das décadas anteriores, bem como lidar com um cenário heterogêneo e cada vez mais diverso quanto aos profissionais que o integram, frente à globalização e estreitamento dos laços sociais (Siqueira \& Machado, 2008) também ocasionados por ela..

\section{Procedimentos metodológicos}

Para atingir os objetivos propostos, foi desenvolvida uma pesquisa de abordagem qualitativa, com finalidade descritiva e que constitui um estudo de caso. A unidade de análise é uma holding educacional de grande porte, neste trabalho denominada ALPHA (também "grupo", "grupo ALPHA" neste artigo), cujo setor de Gestão de Pessoas tem sede em Belo Horizonte.

A ALPHA teve início em 2003, com a aquisição de uma organização que era mantenedora de uma tradicional instituição de ensino superior da capital mineira, criada e administrada desde a década de 1970 por empresários da região sul do Brasil. Em 2006, os acionistas fundadores adquiriram uma organização de Santos, São Paulo, que era mantenedora de um centro universitário também criado na década de 1970. A partir da nova aquisição, os fundadores realizaram uma reestruturação administrativa, financeira, acadêmica, de imagem e de recursos patrimoniais, com foco na gestão integrada no âmbito financeiro e de recursos humanos, visando supostos ganhos na qualidade do ensino. Em 2009, o grupo adquiriu outro centro universitário em Belo Horizonte, o qual foi criado em 1964 por um grupo de professores, tendo sido considerada uma referência em ensino, pesquisa e extensão. Nos anos de 2010 e 2011, duas das instituições do grupo figuraram entre os três melhores centros universitários privados de Minas Gerais, de acordo com um ranking baseado no Índice Geral de Cursos (IGC) divulgado pelo MEC.

Em 2013, a ALPHA passou a deter a participação de um periódico da área de gestão e passou a promover eventos de gestão empresarial destinados a executivos de grandes empresas, visando a promover a discussão de temas de vanguarda de gestão global, e conta com a participação de conferencistas mundialmente reconhecidos. Em 2014, uma universidade particular de São Paulo, bem como, em 2015, uma nova universidade do sul do Brasil, passaram 
a integrar o grupo, que nesse momento já era considerada uma bolding educacional de grande porte, composta por 18 campi, com atuação em vários níveis de ensino, com prioridade para o ensino superior, no qual oferece cursos de graduação e pós-graduação stricto e lato sensu.

O instrumento de coleta de dados foi constituído por entrevistas semiestruturadas aplicadas aos empregados do setor de Gestão de Pessoas da organização e um empregado do setor jurídico. As entrevistas foram colhidas no local de trabalho dos gestores de pessoas e frequentemente a fala de um entrevistado era acrescida de observações registradas pelos demais. Portanto, considera-se que foram realizadas entrevistas individuais e coletivas com gestores e empregados do setor de Gestão de Pessoas e do setor jurídico, as quais foram gravadas, transcritas e submetidas à análise de conteúdo.

Após a leitura das entrevistas realizadas, foi feita a codificação dos dados, decidindo-se pela definição das atividades típicas do setor de Gestão de Pessoas e pelo acréscimo de outras atividades que usualmente não compõem o corpo de ações especificas do setor, mas que fazem parte do contexto das bolding educacionais de grande porte. Portanto, as categorias identificadas foram as seguintes:

1. Levantamento das características da localidade;

2. Definição da estrutura da IES e medidas relacionadas;

3. Realização das atividades próprias do gestor de pessoas;

4. Dificuldades encontradas na operacionalização da Gestão de Pessoas;

5. Contatos e decisões tomadas em colaboração com o setor jurídico da instituição.

Considerando-se a amostra de entrevistados, decidiu-se adotar a indicação Sujeito estratégico (SE) para as falas oriundas de pessoas que atuam no nível estratégico do setor de Gestão de Pessoas e a indicação Sujeito Operacional (SO), para falas advindas de pessoas que atuam no nível operacional do setor. Sujeito Jurídico (SJ) foi adotado para fala do representante do setor jurídico.

A análise dos dados coletados foi feita mediante um modelo de análise do discurso do sujeito coletivo. Assim, em lugar de levar em conta apenas falas individuais isoladas, foram consideradas as entrevistas coletivas, tendo-se o cuidado de caracterizar falas advindas de pessoas que atuam na parte estratégica da Gestão de Pessoas (SE), a fala de pessoas que atuam na parte operacional do referido setor $(\mathrm{SO})$, além de informações obtidas por meio de representante do setor jurídico (SJ).

\section{Apresentação e análise dos resultados}

As entrevistas individuais e coletivas realizadas com empregados do setor de Gestão de Pessoas e do setor Jurídico foram gravadas, transcritas e submetidas à análise de conteúdo. Após a leitura das transcrições, foi feita a codificação dos dados, decidindo-se pela definição das atividades típicas do setor de Gestão de Pessoas e pelo acréscimo de outras atividades que usualmente não compõem o corpo de ações especificas do setor, mas que fazem parte do contexto das holdings educacionais de grande porte. Assim, foram definidas as categorias de análise listadas na metodologia.

O que se tenta demonstrar, nesta análise de resultados, é a diferença entre as atividades tradicionalmente assumidas pelo setor de Gestão de Pessoas de uma organização e as atividades que no caso estudado passam a ser exercidas por estes profissionais num contexto atual de atuação multidisciplinar exigido pelo mercado. É oportuno, para tanto, lembrar das atividades que constituem o escopo de atuação do setor de Gestão de Pessoas, conforme apresentadas por Husek, Stefano e Grzeszczeszyn (2008).

\section{Categoria 1: Levantamento das características da localidade}


A sede da organização educacional que foi objeto desta pesquisa, que é identificada como ALPHA, é localizada em Belo Horizonte, mas há instituições de ensino a ela pertencentes em várias cidades brasileiras. Por este motivo, os profissionais do setor de Gestão de Pessoas se deslocam para diferentes pontos do país, onde são adquiridas e funcionam novas unidades, ou são adotadas diferentes medidas e desenvolvidos novos programas.

Nós atualmente estamos com o Brasil todo. Sendo a central aqui em Belo Horizonte. O Departamento Pessoal cuida do Sul, aqui em Minas Gerais tem todos os polos, existem unidades em São Paulo e Santos, onde as escolas são muito grandes. (SO)

Ao chegarem à cidade, inicia-se um esforço de divulgação das características da organização mantenedora, seus valores e princípios, o que é feito junto com o setor de Marketing. Essas medidas têm grande relevância, porque devem tornar clara a existência de uma organização forte do ponto de vista estratégico e pedagógico naquela região ou cidade. Repassar esta mensagem é indispensável para sensibilizar a população local, conforme apontam os representantes.

Desse modo, as atividades de profissionais do setor de Gestão de Pessoas deste grupo educacional se diferenciam daquelas que são típicas do profissional de uma organização tradicional.

Hoje, se abrimos uma nova unidade, seja ela orgânica ou fruto de uma nova aquisição, primeiro temos que ir para a cidade no intuito de conhecê-la, conhecer seu perfil econômico, sua estrutura e daí temos uma pessoa que fica por conta disso, que trabalha comigo, que também é da Gestão de Pessoas. Ela é psicóloga e fica responsável pelas novas unidades. Dessa forma, ela vai para a cidade quando e quando ela não vai, eles trazem para ela o que colheram de informação e a partir disso, começamos a pensar em uma estrutura mínima para que possamos funcionar. Feito isso, fazemos uma divulgação pela cidade, com isso temos que conhecer a prefeitura da cidade para podermos entender como que funciona, as empresas da cidade que mantêm relacionamento com a escola. Aí definimos o perfil das pessoas para que possamos fazer a divulgação das vagas e também da data em que vamos até a cidade. Divulgamos um e-mail que temos que é para onde as pessoas mandam currículo. (SE)

Recorrendo às atividades propostas por Huzek, Stefano e Grzeszczeszyn (2008) para o gestor de pessoas, a primeira observação que se pode realçar é que esta atividade não compõe usualmente o perfil desse profissional. Trata-se, como exposto pelas entrevistadas, de uma atividade do gestor administrativo e inclui entre os comportamentos desejados do Gestor de Pessoas a disponibilidade para deslocamentos frequentes por diferentes estados e o contato com órgãos que excedem os limites organizacionais: prefeituras, comércio da cidade, empresas que mantêm relacionamento com a organização educacional, imprensa local, dentre outras.

A ampliação das atividades do Gestor de Pessoas fica evidente também quando se verifica que não apenas o setor de Marketing se envolve com a divulgação, mas também a área de Gestão de Pessoas:

Eu me lembro que quando isso começou, a captação não era um problema da instituição inteira, era um problema do marketing, porque esse setor que tinha que se preocupar em captar, em promover, em colocar a marca em alta. Quando isso aconteceu, tirou todos da zona de conforto em um primeiro momento, porque todos tiveram que correr atrás da captação de alunos e com isso todos tinham que pensar nisso, para tentar reverter esse quadro que foi essa evasão que começou de forma descontrolada. (SE)

Outra necessidade que se impõe é o preparo adequado dos vários setores, a fim de que estejam alinhados e alcancem os objetivos propostos em cada localidade. A fala do representante do setor Jurídico explicita este esforço da organização, fazendo referência à união de todos os setores para obtenção do resultado.

Um objetivo advindo de todas essas reformulações é a busca por comunicação clara e eficaz entre os setores, de forma que os processos sejam melhor iniciados e finalizados, sendo que o Jurídico da companhia, de forma pioneira, tem criado projetos autônomos para cobrir eventuais desconexões entre este e as áreas. Para tanto, tem-se adquirido programas modernos para automatização de processos, para que se possa evitar um gasto de tempo exacerbado em tarefas simples e seja possível buscar uma atuação mais próxima das áreas e atenta à prevenção antes da mitigação. (SJ) 
Como a sede do setor de Gestão de Pessoas fica localizada em Belo Horizonte, empregados da área operacional registraram que frequentemente se deslocam para São Paulo, bem como para outros estados onde tenham sido adquiridas ou funcionam novas unidades. Infere-se, portanto, que um diferencial no trabalho do gestor de pessoas numa bolding educacional de grande porte seja a disponibilidade plena para o deslocamento a diferentes localidades, o que geralmente não seria exigido deste profissional numa empresa tradicional. Além disso, em casos pontuais, é necessário o desenvolvimento de atividades específicas do setor administrativo e Marketing.

\section{Categoria 2: Definição da estrutura de cada IES e medidas relacionadas}

Quando é feita a aquisição de uma nova instituição educacional, são desenvolvidas atividades destinadas a preparar o início de seu funcionamento, como relatam os entrevistados.

A partir do primeiro contato com a nova instituição, começamos a pensar em uma estrutura mínima para que possamos funcionar: uma pessoa na portaria, uma pessoa da limpeza porque se tem obra tem também muita coisa para limpar. Assim, pensamos em uma estrutura mínima e colocamos unidades de tamanho RN, que é recém-nascido, P, M, G e GG. Então a unidade que ainda vai nascer, que sabemos que vai existir, mas que ainda não está em funcionamento, pensamos no porteiro e em uma pessoa para a limpeza. Feito isso, fazemos um levantamento do perfil das pessoas que terão de ser contratadas, fazemos uma divulgação pela cidade, e divulgamos um email que temos que é para as pessoas mandarem currículo. (SE)

Um desafio novo que se apresenta é relacionado à definição do perfil dos profissionais e à escolha daqueles que já atuavam na IES e que deverão ser mantidos. Por outro lado, a medida se relaciona também com a dispensa daqueles cujos perfis não coincidem com a necessidade institucional, como esclarece o pessoal do nível estratégico.

Toda a equipe continua, até porque não podemos fazer uma virada tão agressiva. Por exemplo, quando adquirimos a XY, que é uma instituição do interior de Minas, nós mantivemos toda a equipe até maio, que foi quando rodamos a integração, que é um processo em que se coloca todos os processos da ALPHA dentro dessa nova aquisição. Então mantemos toda a equipe e toda a estrutura; tudo funciona como sempre funcionou normalmente até que rodem a integração e a partir do momento que isso ocorre tem áreas que provavelmente vão deixar de existir e tem áreas que vão surgir. Quando uma área deixa de existir, aqueles que trabalham nela podem ser realocados para outras áreas em outras unidades, porque tem pessoas que podem mudar de cidade, então ficamos nesse movimento. (SE)

Na perspectiva das funcionárias do nível operacional, a explicação é a seguinte:

Eu acredito que eles adéquam o que é da outra instituição com o que é usado no Grupo ALPHA. Por exemplo, na instituição recém adquirida a folha de pagamento do professor ainda é fechada lá, ou seja, não é fechada pelo grupo acadêmico daqui, mas se usam os métodos do Grupo ALPHA. (SO)

Ao responder ao desafio de organizar o quadro de pessoas que deverão trabalhar na instituição recém adquirida, os gestores de pessoas são levados a inovar e englobar em sua atuação função administrativa estratégica, dedicandose ao cálculo dos custos de uma estrutura organizacional que funcione sem determinar grandes gastos.

Começamos a nos ver em uma situação de contenção de gastos mesmo. Tínhamos que escolher entre dar uma promoção por uma questão de mérito ou segurar da forma que estava porque mais para frente não teríamos como manter aquela pessoa. Então começamos a estudar muito antes de promover, de abrir uma vaga, de aumento de headcount, começamos a pensar em contenção de gastos sem pensar em demissão. Dessa forma, a primeira coisa que fizemos foi que sempre tivemos uma equipe, mas não sabíamos se era a adequada. Observando essas informações, começamos a fazer um estudo de quantificar mesmo, pensando na quantidade de pessoas que precisaríamos para fazer determinada atividade. Com isso, pensamos em ter um controle do headcount na ponta dos dedos, controlando todas as áreas que eram abertas ou por desligamentos ou por pessoas que eram promovidas. Feito isso, começamos um estudo de área, para ver onde podíamos não aumentar o quadro e conseguir rodar com a mesma eficiência. (SE) 
Dias e Araujo (2008) se referem a essas medidas como uma modalidade de gerência estratégica, realçando que num mundo marcado pela competitividade a eficiência dos funcionários, esta atitude denota eficiência na organização.

No tocante ao pessoal docente, a questão que coube à Gestão de Pessoas está relacionada aos cursos que são mantidos, aos recursos repassados pelo Governo e à necessidade de manter a instituição funcionando. É sabido que a partir de 2017 recursos do FIES foram reduzidos e houve redução significativa de alunos, levando à eliminação de turmas e dispensa de docentes.

(...) desapareceram turmas e o número de desligamentos de professores aumentou e atualmente não, está mais controlado, mas naquela época foi um momento onde nos vimos demitindo mais e contratando menos. Me lembro de treinamentos de boas vindas de professor em que tínhamos 200, 300 professores e depois tínhamos 40 entrando no semestre. Como não tinha turma, não tínhamos quantidade de alunos suficientes para fechar turma, o que influenciou também na quantidade de professores contratados. (SE)

Essas observações remetem ao que é mencionado por Freitas Filho, Campos e Sousa (2015) que consideram que a inovação constitui uma alternativa de tema estratégico para as organizações e estão ligadas diretamente à Gestão de Pessoas. Também Gülsoy (2013) registra que a inovação organizacional está intimamente ligada às políticas e práticas de recursos humanos, aspectos que são mencionados pelos sujeitos.

Possivelmente, um grande desafio vivenciado pelos empregador do setor de Gestão de Pessoas dessa organização educacional de grande porte tenha sido a mudança associada à crise dos recursos destinados ao financiamento da educação, como veremos na categoria que trata das dificuldades enfrentadas pelo setor.

\section{Categoria 3: Realização das atividades próprias do gestor de pessoas}

Depois de conhecida a cidade onde se situa a nova unidade, definida a estrutura da IES, e sua relação com a mantenedora, são tomadas providências que são específicas do gestor de pessoas, começando pela captação de pessoas e início dos processos seletivos, como relata uma pessoa entrevistada.

\footnotetext{
À partir daí, começamos o processo de entrevista. Quando é de longe fazemos por Skype e fazemos a contratação por Sedex, as pessoas mandam a documentação, o nosso Departamento Pessoal avalia e daí chama a pessoa para fazer um exame admissional. Isso se não tivermos nenhuma clínica nessa cidade que possamos ter uma parceria. Com isso, pensamos em uma estrutura mínima, e ai depois lançamos o vestibular, que é feito com alguém do marketing, nem que seja alguma promoção em eventos, que divulgue pela cidade e em seguida pensamos em um assistente administrativo ou em um líder de promoção em eventos para que comecemos a divulgar a instituição dentro da cidade. Depois disso, nós pensamos em uma pessoa de Gestão de Pessoas, que vai ter que contratar alguém da região e assim pensamos de acordo com as demandas que vão surgindo. (SE)
}

Como fica claro nessa exposição, o trabalho do gestor de pessoas se vincula, ainda, ao que se desenvolve no setor de Marketing, ao qual caberia divulgar a instituição, de modo a torná-la atraente para os residentes na localidade ou em outras próximas. Verifica-se que além de conhecer a localidade, o profissional de Gestão de Pessoas precisa estabelecer uma relação próxima do setor de Marketing e ainda promover a divulgação da instituição na cidade. Mesmo que seja uma IES já conhecida na localidade, as novas características institucionais precisam ser apresentadas à população local.

$\mathrm{Na}$ definição das atividades a serem desenvolvidas, as pessoas entrevistadas mencionam a existência de várias reuniões; citam contatos com a supervisora, com a gerência do Gestão de Pessoas e com o grupo de trabalho que vai implantar o novo modelo. Essas reuniões têm como objetivo buscar melhorias, como é lembrado por uma pessoa representante do nível operacional:

Nós trabalhamos com o sistema da soft trading, que é o fator RH. E temos o suporte deles, que são um pessoal de São Paulo, eles estão sempre vindo para cá sempre para ver o que pode ser melhorado no 
sistema. Tem muito o que melhorar ainda, mas buscam sim estar sempre em reuniões discutindo o que pode ser melhorado. (SO)

No contato com a cidade, as pessoas entrevistadas mencionaram que buscam pessoas e empresas que realizam trabalhos que podem facilitar o delas, envolvendo-os com o processo de captação de pessoas, com a seleção e posteriormente com o treinamento e desenvolvimento dos profissionais.

A gente procura pessoas que cuidam do processo de seleção, que fazem treinamento, que aplicam testes e fazem divulgação de vagas. (SE)

Outra atividade própria do setor de Gestão de Pessoas é referente à implantação da cultura organizacional própria da mantenedora, de modo que todos os funcionários da organização tenham conhecimento dos valores institucionais, dos objetivos e metas que são definidos.

Logo que se tem a definição da estrutura de uma unidade e se define quem vai trabalhar nela, são organizados eventos destinados a falar da missão, da visão, dos objetivos e metas da instituição. É feita também uma apresentação da organização como um todo. (SO)

Quando questionadas sobre a terceirização de serviços, as pessoas entrevistadas comentaram sobre acordos que por vezes são realizados. Foi citada uma situação em que um grupo de funcionários precisou ser desligada e foi necessário encontrar uma solução para o caso, que em última análise foi conduzida também pelo setor Jurídico:

(...) as homologações do pessoal da infraestrutura que foram desligados. Só que teve uma parceria com a empresa, em que indicaram um pessoal que saiu daqui, para essa outra empresa, sendo que não conseguiram aproveitar a todos, mas uma grande parte do pessoal que foi desligado. emitidos e na preocupação com estes. Não era uma empresa do grupo, se não me engano foi um acordo que eles fizeram, que foi com o ISS. Uma empresa terceirizada que ia assumir a limpeza e com isso, nós acordamos que parte do pessoal que estava sendo desligado seria terceirizado por eles. (SO)

As consequências do enfrentamento dessas dificuldades são devidamente citadas na próxima categoria.

\section{Categoria 4: Dificuldades encontradas na operacionalização da Gestão de Pessoas}

Uma grande dificuldade se liga à cultura das localidades onde são instaladas as novas unidades. Conhecer a cultura é um novo desafio do Gestor de Pessoas:

Olha, é muito difícil quando se cresce muito e muito rápido, continuar, se desdobrar em todos os lugares em que a instituição estão os valores, a visão e a missão. É a parte mais difícil que é a cultura, a socialização organizacional. É a parte mais difícil, porque por exemplo você vai em Jataí, que é muito longe daqui e é muito complicado, levar para lá o que vivemos aqui. Somos nós que contratamos professores para lá, tudo, tudo é o Gestão de Pessoas daqui. É muito difícil, sendo a parte mais difícil quando você cresce muito, que é você levar a cultura, por ser muito regionalizado e a região ser muito diferente, sendo bem complicado. (SE)

O crescimento do ensino superior na rede privada esteve, como foi mencionado, relacionado à oportunidade de reorganização das instituições existentes e de criação de novos cursos. Os modelos de financiamento para os alunos permitiram, por sua vez, que as instituições tivessem um significativo número de alunos matriculados e frequentes. Entretanto, a partir do ano de 2017, uma crise se instalou em razão de dificuldades no repasse de recursos destinados ao financiamento dos cursos (crédito educativo, FIES e outros) se tornaram escassos ou nulos.

Dessa forma, nos vemos numa situação complicada porque precisávamos não ter gastos, mas ao mesmo tempo, pensávamos em algo que auxiliasse na captação de alunos e nessa época foi criada a área do comercial, pois não tínhamos essa área específica dentro da instituição. Nesse momento difícil foi pensada a necessidade de criar essa área, no intuito de trazer pessoas. Resumindo, percebi que esse momento de crise foi difícil e delicado, mas ao mesmo tempo foi quando conseguimos ver além, o mais que poderíamos fazer. Onde está indo o dinheiro que recebemos? Podemos trazer esse aluno que não 
terá mais financiamento? Então, digo que nesse momento de crise foi quando conseguimos pensar em uma nova estrutura e nos reinventarmos. (SE)

A operacionalização da Gestão de Pessoas tornou-se um desafio diante de medidas adotadas pelo Governo: mudanças na legislação, exigências referentes ao reconhecimento de cursos, exigências referentes ao corpo docente.

Uma grande dificuldade é compor o corpo docente com as características exigidas: doutores, mestres, especialistas e nem sempre existem na localidade pessoas com esta formação. Então, temos de partir para a procura de profissionais. (SE)

Quando questionados sobre o corte dos recursos do FIES e como isso afetava a dinâmica da empresa, impondo a redução de gastos, as pessoas entrevistadas relatam o interesse no bem estar do trabalhador, que aparece como uma preocupação vigente. Nessa situação, é necessário ter cautela, a fim de que o funcionário não seja prejudicado e apenas em último caso seja desligado da empresa.

O que percebi em minha atividade é que houve um corte um pouco elevado, e víamos o tanto que as pessoas estavam abatidas, o quanto sentiam com essa redução. Ficamos chateados, porque penso que poderia ser eu, nos colocamos no lugar da outra pessoa, ainda mais o pessoal podemos dizer que mais humildes, os funcionários que percebemos que necessitavam mesmo daquela renda, o pessoal da limpeza, por exemplo. Houve um cuidado com eles também, porque querendo ou não são pessoas muito queridas que nos tratavam super bem e que sentimos muita falta, pois são muitos anos de empresa. Assim, eles tiveram esse cuidado de fazer essa parceria com o ISS, para que pudesse indicar essas pessoas em outras instituições. Sei que várias pessoas foram admitidas no Pitágoras, em que eles vinham fazer a homologação e já nos informavam que eles já estavam sendo admitidos em outra empresa. Então, foi tudo de imediato. (SO)

A necessidade de se delinear uma visão abrangente do funcionamento da nova IES é um desafio novo enfrentado pelos gestores de pessoas dos grandes grupos educacionais e responder satisfatoriamente às dificuldades encontradas requer inovação, adotada para que essas organizações de grande porte perseverem.

O representante do setor Jurídico expôs de forma ampla e objetiva a grande dificuldade de se gerenciar uma organização educacional de grande porte:

Quanto maior a organização, maior se torna o desafio de manter os processos fluidos, eficazes e velozes. Não é diferente na ALPHA. Temos hoje uma série de setores especializados em diversas frentes de atuação. Para utilizarmos informações mais fáticas, os próprios setores do Gestão de Pessoas e da Diretoria Jurídica também se subdividem. Esse último, por exemplo, é internamente segmentado em três coordenações: Cível, Trabalhista e Governança Corporativa/Societário. Devido a essa especificidade de tarefas encontrada em todo o grupo, a comunicação entre as áreas pode se perder ou se fragmentar no percurso de uma ponta à outra. Percebe-se, por exemplo, que muitas áreas não sabem o que faz o Jurídico da própria instituição na qual trabalham. Dentre os que sabem, poucos são capazes de citar mais do que 3, 5 funções exercidas pelo setor, quando, na verdade, existe um grande leque de atividades. Desse desconhecimento, nasce o medo infundado, que faz com que alguns ajam como se o setor fosse composto por não humanos, melhores ou melhor qualificados que o restante da companhia. Sentimos que por mais que se façam vídeos explicativos, FAQs, por mais que se responda a chamados, se compareça a reuniões, essa proximidade não alcança uma parte dos colaboradores, que sentem que não têm acesso direto ao setor. (SJ)

Assim, percebe-se que a função do Gestão de Pessoas de se implementar e difundir a cultura empresarial da organização também perpassa pela ampla divulgação e apresentação de processos administrativos e setores, de forma que os próprios empregados, estejam eles em uma cidade, ou noutra, estejam cientes de como funcionam os processos administrativos básicos e atinentes a todos os empregados da empresa.

Dessa forma, é possível que a empresa se apresente como unida, fluida, e que os empregados, como ressaltado pelo Sujeito Jurídico, não temam infundadamente as atividades de outros setores, por mero desconhecimento das funções destes últimos. 


\section{Categoria 5: Contatos e decisões tomadas junto com o setor Jurídico da instituição}

O setor Jurídico da instituição foi ouvido e registrou a seguinte observação:

O que se tem visto recorrentemente na reformulação dos setores de grandes organizações poder-se-ia resumir em duas palavras: enxugamento e eficiência. O primeiro termo trata do corte de pessoal, em especial mais antigo e com salários vultuosos e posições altas da carreira na empresa. Para os postos vacantes, se contrata empregados em início da vida profissional, visando economia e inovação, porém, acarretando em falta de know-how e perda de informações sobre processos em meio a isso. O segundo termo, eficiência, demonstra o que se espera dessas novas mentes pensantes contratadas para suprir, às vezes, 2 ou 3 postos ao mesmo tempo, cumulando funções antes exercidas por vários profissionais. Nesse processo, ao se buscar enxugamento de pessoal e diminuição da folha de pagamento, encontrase também precarização do trabalho e maior rotatividade de empregados. (SJ)

É importante registrar que uma inovação adotada na bolding educacional de grande porte estudada é que o setor Jurídico age em constante relacionamento com o setor de Gestão de Pessoas, estando informado sobre as atividades desenvolvidas pelo setor e pronto a atuar de forma complementar:

Em meio ao panorama brevemente narrado acima, as diversas frentes do Gestão de Pessoas do Grupo ALPHA buscam formular estratégias para cumprir o que lhes é proposto pela Diretoria, como a contratação de profissionais qualificados - às vezes qualificados demais para o salário oferecido - por remuneração abaixo do mercado, elaboração de políticas de benefícios e bem-estar com orçamento irrisório e a insatisfação de colaboradores que se veem estagnados na carreira, pela falta de incentivos e progressões verticais e horizontais, devido ao congelamento de verbas. (SJ)

A parceria é explicitada pela fala de representantes do setor de Gestão de Pessoas e do setor Jurídico:

Em meio a esse cenário, há uma relação contínua de diálogo entre o Gestão de Pessoas e o setor Jurídico da instituição, na busca de aconselhamento e respostas. O Jurídico é consultado antes de muitos passos importantes que são tomados pelo Gestão de Pessoas, às vezes, com meses de antecedência. Agem dessa forma para evitar litígio de empregados e ex-empregados, irregularidades que eventualmente são fiscalizadas pelo Ministério do Trabalho e Emprego e, de forma geral, a insatisfação dos empregados administrativos e docentes. (SE e SJ)

Assim, o Jurídico é consultado quando há intenção de modificar benefícios (se podem ou não, bem como formas de fazê-lo), quando há intenção de dispensar determinado empregado, para verificação se está em alguma situação jurídica de estabilidade ou garantia de emprego (cipistas, pessoas em período de pré-aposentadoria, em tratamento de doença grave sem alta médica, retornando de licença do INSS por acidente de trabalho ou doença ocupacional) ou quando há ocorrência de alguma falta considerada suficientemente grave para se aplicar dispensa por justa causa, mas temem que seja medida demasiado penosa para a conduta aos olhos da Justiça do Trabalho. Por outra via, também solicitam análise de contratos diversos de projetos do Gestão de Pessoas pensados para os colaboradores da empresa, como prestadores de serviços autônomos e empresas de eventos, dentre outras situações que dependem do Direito Civil ou do Trabalho. (SJ)

De acordo com o se registrou, verifica-se que a atuação de profissionais da área de Gestão de Pessoas de uma holding educacional de grande porte implica, atualmente, numa abordagem sistêmica sobre o ambiente organizacional como um todo, perpassando pela cultura, pela crescimento da organização para a qual trabalham e a aquisição e abertura a aprendizado de novas áreas de conhecimento. Dentre essas áreas, pode-se citar a Administração em geral, Contabilidade e Economia, Psicologia, relações humanas, noções de Marketing e, como já repisado pelo artigo, legislação trabalhista normas legais como um todo, senão vejamos os apontamentos do representante Jurídico:

Apesar da melhoria de processos, comunicação, mapeamento de tarefas, redesenho de setores, criação de setores inteiros voltados para atuação estratégica e de melhoria contínua, ainda há 
ocorrência de diversos problemas que poderiam ser facilmente evitados com o diálogo entre o setor envolvido e o Jurídico. O Gestão de Pessoas não é uma exceção a essa regra: muitas situações levadas à Justiça do Trabalho poderiam ser evitadas por meio de esclarecimentos e diálogo junto ao Departamento Jurídico antes da tomada de decisão, elaboração de termo para formalização do que foi acordado entre as partes, ciência sobre como agir em situações que envolvam outros colaboradores da instituição, dentre outras. Devido a isso, o que se busca para o Gestão de Pessoas frente ao Jurídico é o estreitamento constante de laços, em uma mudança efetiva de cultura, de forma que ambas as áreas entendam que fazem parte de um mesmo grupo, com objetivos convergentes e interesses comuns, cada uma atuando em sua própria frente para resolução conjunta de um mesmo problema. Dessa forma, será possível evitar diversas consequências advindas de uma estratégica formulada pensando-se somente na gestão de pessoas, ou somente nos aspectos legais, buscando entendimento global e amplo sobre o assunto em pauta. (SJ)

Devido a isso, percebe-se que se espera do Gestão de Pessoas, ainda, que estabeleçam relações fortes de parceria com profissionais do setor Jurídico, de forma a se evitar eventuais questionamentos judiciais. Apesar disso, sabese que essa necessidade de proximidade e melhor alinhamento não é apenas do setor Jurídico, mas da organização como um todo.

Como bem pontuado pelo representante do setor Jurídico, os processos de uma bolding educacional de grande porte tendem a ser complexos e envolverem diversos fatores, procedimentos e setores, sendo que o alinhamento entre estes últimos se torna, por vezes, insuficiente frente ao número de empregados ou à carga horária diária de trabalho.

Acredita-se que essa mesma necessidade de proximidade poderia ser verificada com outros setores não explorados nesta pesquisa, de forma que desejam estar em contato e familiarizados com os processos seguidos pela Gestão de Pessoas, e, inclusive, pela organização como um todo. Já para a Gestão de Pessoas, por vezes tornar-se-ia inviável conhecer todos os processos da sede empresarial, em Belo Horizonte, e ainda os que acontecem em cidades do interior de estados do Sul ou Sudeste do Brasil, por exemplo, por vezes longe dos olhos e da rotina administrativa nuclear.

Também caberia aos profissionais do Gestão de Pessoas, por fim, se inteirar da e adaptar a cultura local em cada dessas das novas cidades nas quais a holding adquire instituições, de forma a torná-las uniformes, ou mais próximas, do que se pratica na sede mineira da organização.

\section{Considerações finais}

A globalização, avanço tecnológico e do modo de trabalho no século XXI têm ampliado, ou alterado, o escopo de atuação de profissionais e setores organizacionais como um todo. A Gestão de Pessoas do início do século já não é a mesma dos anos 2010, bem como essa não é a mesma da que desponta nos anos 2020. Essa mudança de posicionamento está em linha com os achados de Goulart (2010), sobre a necessidade de mudança para acompanhamento dos movimentos sócio-político-econômicos.

Os achados desta pesquisa indicam que a Gestão de Pessoas de holdings educacionais de grande porte tem agido, atualmente, para além das funções típicas que um esperaria da Gestão de Pessoas, baseando-se nas funções típicas abordadas por Huzek, Stefano e Grzeszczeszyn (2008). Isso se deveria à necessidade de se delinear uma visão abrangente do funcionamento das novas IES e da holding como um todo, sendo o desafio da Gestão de Pessoas dos grandes grupos educacionais responder satisfatoriamente, se utilizando da inovação, adotada para que essas organizações de grande porte perseverem. 
Para que uma holding educacional de grande porte, como a estudada, se apresente fluida e com processos em alto grau de implementação, é função esperada do Gestão de Pessoas a difusão da cultura empresarial da organização, com a divulgação e apresentação de processos administrativos e setores, de forma que os próprios empregados, estejam eles em uma cidade, ou noutra, dentre as diversas localidades onde a bolding controla instituições de ensino, estejam cientes de como funcionam os processos administrativos básicos e atinentes a todos os empregados da empresa.

Verificou-se que a atuação de profissionais da área de Gestão de Pessoas de uma holding educacional de grande porte implica uma abordagem sistêmica sobre o ambiente organizacional como um todo, além de abertura a aprendizado de novas áreas de conhecimento, como Administração em geral, Contabilidade e Economia, Psicologia, relações humanas, noções de Marketing e, como destacado pelo artigo, de legislação trabalhista e normas legais. Esses achados estão em linha com o abordado por Tonelli, Lacombe e Caldas (2002), ao afirmarem que a área de recursos humanos ganha destaque pela sua atuação múltipla.

Destaca-se, ainda, a divisão do Gestão de Pessoas da organização, para questões operacionais e estratégicas, o que está em linha com a tese defendida por Dias e Araújo (2008), sobre a necessidade das empresas adotarem essa postura estratégica clara, bem como de se tomar medidas de gerência estratégica, como é o caso da divisão do Gestão de Pessoas da holding educacional de grande porte estudada, em área operacional e área estratégica.

Espera-se do Gestão de Pessoas, ainda, que estabeleçam relações fortes de parceria com profissionais de outros setores da organização, neste estudo representados pelo setor Jurídico, de forma a se criar proximidade e melhor alinhamento na organização como um todo. Acredita-se que essa mesma necessidade de proximidade poderia ser verificada com outros setores não explorados nesta pesquisa, de forma que desejam estar em contato e familiarizados com os processos seguidos pela Gestão de Pessoas, e, inclusive, pela organização como um todo.

Os processos de uma holding educacional de grande porte tendem a ser complexos e envolverem diversos fatores, procedimentos e setores, sendo que o alinhamento entre estes últimos se torna, por vezes, insuficiente frente ao número de empregados ou à carga horária diária de trabalho. Já para a Gestão de Pessoas, por vezes tornar-se-ia inviável conhecer todos os processos da sede empresarial, em Belo Horizonte, e ainda os que acontecem em cidades do interior de estados do Sul ou Sudeste do Brasil, por exemplo, por vezes longe dos olhos e da rotina administrativa nuclear.

Também caberia aos profissionais do Gestão de Pessoas, por fim, se inteirar da e adaptar a cultura local em cada dessas das novas cidades nas quais a holding adquire instituições, de forma a torná-las uniformes, ou mais próximas, do que se pratica na sede mineira da organização.

As atividades aqui abordadas não trazidas por Huzek, Stefano e Grzeszczeszyn (2008) como nucleares da Gestão de Pessoas se configuram, portanto, como uma inovação nos processos atuais da área, sendo esta defendida por Freitas Filho, Campos e Sousa (2015) como necessária no contexto atual de competitividade e procura pela liderança de mercado.

A análise de apenas um grupo educacional, o seu grande porte e a participação de apenas mais um setor da organização se constituem, porém, como limitações do presente estudo, sendo que se sugere, por exemplo, que novas pesquisas sejam realizadas levando em conta holdings educacionais de pequeno e médio porte, bem como sejam exploradas novas conexões entre diferentes setores organizacionais.

\section{Referências}

Albuquerque, L. G. (1987). O papel estratégico de recursos humanos. São Paulo, 1987. Tese (Livre Docência Faculdade de Economia, Administração e Contabilidade) - Universidade de São Paulo.

Albuquerque, L. G. (1992). Competitividade e recursos humanos. Revista de Administração, 27(4), 16-29.

Anthony, W. P., Perrewé, P. L., \& Kacmar, K. M. (1996). Strategic resource management. San Diego: Harcourt Brace \& Co. 
Barros, A. M. (2017). Curso de Direito do Trabalho. 11. ed. LTr, São Paulo.

Bauman, Z. (1999). Globalização: as consequências humanas. Jorge Zahar Editor, Rio de Janeiro.

Boucinhas Filho, J. C. (2008). Discriminação por sobrequalificação. Dissertação (Mestrado em Direito) - Universidade de São Paulo, São Paulo.

Comparato, F. K. (2017). A Afirmação Histórica dos Direitos Humanos. 11. ed. Saraiva, São Paulo.

Dias, M. D., \& Araújo, G. C. (2008). Tendências na Gestão de Pessoas: uma visão estratégica. In SEGeT Simpósio de Excelência em Gestão e Tecnologia, 5. Anais: AEDB. Recuperado em 11 de julho, 2020, de https://www.aedb.br/seget/arquivos/artigos08/573 Artigo Gestor RH[1].pdf.

Dworkin, R. (2012). A virtude Soberana - a teoria e a prática da igualdade. 2. ed. Martins Fontes, São Paulo.

Fischer, A. L. (2001). O Conceito de Modelo de Gestão de Pessoas - Modismo e Realidade em Gestão de Recursos Humanos nas Empresas Brasileiras. In Dutra, J. S. (Org.), Gestão por Competências: Um Modelo Avançado para Gerenciamento de Pessoas. São Paulo: Editora Gente.

Fleury, M. T. L. (2002). As pessoas na organização. 11. ed. São Paulo: Gente.

Freitas Júnior, A. R. (2006). Direito do trabalho e direitos humanos. BH, São Paulo.

Freitas, F. L. (2013). Gestão da inovação: teoria e prática para implantação. São Paulo: Atlas.

Freitas, F. L., Campos, T., \& Souza, J. A. (2015). Avaliação do grau de inovação do processo de gestão de pessoas em uma empresa fabricante de eletrodomésticos. Strategic Design Research Journal, 8(2), 94-103.

Galdino, F. (2005). Introdução à Teoria do Custo dos Direitos: direitos não nascem em árvores. Lumen Iuris, Rio de Janeiro.

Gomes, F. R. (2008). O Direito Fundamental ao Trabalho: Uma Miragem Discursiva ou uma Norma Efetiva? In Sarmento, D., (Coord.) Direitos Sociais: Fundamentos, Judicialização e Direitos Sociais em Espécie. Rio de Janeiro, Lumen Juris.

Goulart, I. B. (2010). Psicologia organizacional e do trabalho: teoria, pesquisa e temas correlatos. São Paulo: Casa do Psicólogo.

Gülsoy, A. T. (2013). Human resource practices of an emerging-market multinational: implications for enhancing organizational innovation. Procedia: Social and Behavioral Sciences, 75(3), 498-507.

Huzek, D., Stefano, S. R., \& Grzeszczeszyn, G. (2008). Perfil dos Gestores de Pessoas e Suas Práticas. In SEGeT - Simpósio de Excelência em Gestão e Tecnologia, 5. Anais: AEDB.

Marx, K.; Engels, F. (2000). Manifesto do partido comunista. Vozes, Petropólis.

Miranda, K. F., \& Miranda, H. C. F. (2009). Compreendendo a Gestão de Pessoas. João Pessoa: Administradores.

Morrow, R. A., \& Torres, C. A. (2004). Social Theory and Education: A Critique of Theories of Social and Cultural Reproduction. New York City: State University of New York.

Queiroz, A. C. S., Albuquerque, L. G., \& Malik, A. M. (2013). Gestão estratégica de pessoas e inovação: estudos de caso no contexto hospitalar. Revista de Administração, 48(4), 658-670.

Ribeiro, A. L. (2005). Gestão de Pessoas. 7. ed. São Paulo: Saraiva.

Santos. B. S. (2005). Globaliração: Fatalidade on Utopia?. 3. ed. Afrontamento, Porto.

Siqueira, D., \& Machado, R. A. (2018). Proteção dos direitos humanos LGBT e os princípios consagrados contra a discriminação atentatória. Revista Direitos Humanos e Democracia, 6(11), 167-201.

Tassigny, M. (2004). Ética e ontologia em Lukács e o complexo social da educação. Revista Brasileira de Educação, $25,82-91$.

Tonelli, M. J., Lacombe, B. M. B., \& Caldas, M. P. (2002). Manual de Gestão de Pessoas e Equipes: estratégias e tendências. Vol. 1. São Paulo: Gente.

Ulrich, D. (1998). Os campeões de recursos humanos: inovando para obter os melhores resultados. São Paulo: Futura.

Wright, P., Kroll, M. J., \& Parnell, J. (2000). Administraşão Estratégica. 4. ed. São Paulo: Atlas. 